\title{
Dyeing of Polypropylene Fibers with Disperse Dyes by Supercritical Carbon Dioxide
}

\author{
Shen-Kung Liao, Pi-Shiun Chang and Yan-Chia Lin \\ Department of Textile Engineering, Feng Chia University, 100 Wen Whia Road, Taichung, Taiwan
}

\begin{abstract}
Polypropylene fabrics were dyed under various conditions by supercritical carbon dioxide technology. Amounts of dye absorbed by polypropylene fibers were calculated from the visible spectrum and penetration of dye was observed by microscopy. The result showed dye had diffused into fibers and dye uptake values of carbon dioxide dyeing obtained from visible analysis were much higher than that of water. X-ray and DSC analysis indicated that dyeing behavior of polypropylene with disperse dyes obeyed the free volume model. No obvious damage had happened while fabrics dyeing at $120^{\circ} \mathrm{C}$ in accordance with the TGA and mechanical properties test. Wash fastness was the major problem to be necessary to overcome on this dyeing method.
\end{abstract}

Keyword: Polypropylene, Disperse dye, Supercritical carbon dioxide, Free volume.

\section{Introduction}

Polypropylene has grown rapidly in polymer market is due to its some attractive properties such as low density, high toughness and resilience, excellent chemical and abrasion resistance. These properties make it quite common in home furnishing and industrial applications. ${ }^{[1]}$ However, poor moisture adsorption and the lack of dyeing properties make polypropylene unapplicable in apparent aspect. ${ }^{[2]}$ Hence, many studies on improving the dyeability of polypropylene had been reported. These methods included:(a) fiber chemical treatment by chlorination or bromination to dye fibers with cationic dyes ${ }^{[3,4]}$ (b) adding polar additives to polypropylene and spinning to form acid-dyeable fibers ${ }^{[5-7]}$ (c) copolymerizing polypropylene with acrylate series by irradiating initiation made polypropylene as suitable copolymers to be dyed with basic, disperse, reactive or acid dye ${ }^{[8-13]}$ In recent years, A.Seves and Jir $i$ Akrman et.al had tried to blend polypropylene with either hydrogenated oligocyclopentadiene or wool to study their dyeing results. ${ }^{[14,15]}$ Although these ways had increased the dyeability of polypropylene, their sensitivity to light and possible reduction on mechanical properties, and the most of all, the expensive cost made them hard to be commercialized.

Supercritical carbon dioxide dyeing technology had developed by Saus Wolfgang on dyeing hydrophobic fibers in 1990s because of the economic efficiency and excellent leveling result. ${ }^{[16-18]}$ As carbon dioxide was used, no any additives were necessary for dyeing hydrophobic polyester. Besides, good compatibility between carbon dioxide and disperse dye can give satisfactory result. Hence this technology was populous in recent years. Regarding the hydrophilic natural fibers, A.S.Ozcan and D.M. Lewis et. al had also dyed modified cotton fibers with disperse dyes. The dyeing results also showed very encouraging when cotton fibers were treated by benzoylation. ${ }^{[19]}$ Because carbon dioxide is a hydrophobic and low viscosity gas, it can penetrate into polypropylene fibers much easier than water. This concept had also been proved by Y.T.Shieh et. al in their report. ${ }^{[20]}$ If supercritical carbon dioxide was used in dyeing polypropylene, the results should be expectable due to the excellent permeability of carbon dioxide.

As description stated above are concerned, we tried to dye 
polypropylene with three disperse dyes using carbon dioxide as a solvent and compare the dyeing results with traditional water dyeing specimens by visible spectrum and fastness tests. X-ray, DSC and microscopy analysis were also made to study the relation between dyeing result and fiber structure variation.

\section{Experiment}

\subsection{Material}

The

$$
\frac{45 \times 36}{50 \text { tex } / 103 f \times 56 \text { tex } / 110 f} 2 / 2 \text { weave isotactic }
$$

polypropylene fabric used in filtration was supplied by Chong-Yi trade company. Three kinds of dyes, C.I. Disperse Red 60, C.I. Disperse Orange 76 and C.I. Disperse Yellow 3, were purchased from Yi-Whia and supplied by Yong-Kuang company respectively. Their structures were shown in Figure 1. Before the dyeing was carried out, These dyes were purified by extraction and recrystallization using acetone as a solvent. Element analysis of three dyes were listed in Table1.<smiles>Nc1c(Oc2ccccc2)cc(O)c2c1C(=O)c1ccccc1C2=O</smiles>

C.I.Disperse Red 60<smiles>CCN(CC)c1ccc(N=Nc2c(Cl)cc([N+](=O)[O-])cc2Cl)cc1</smiles>

C.I.Disperse Orange 76<smiles>CC(=O)Nc1ccc(N=Nc2cc(C)ccc2O)cc1</smiles>

C.I. Disperse Yellow 3

Figure 1: Structure of disperse dyes used in this experiment Table 1: Element analysis results

\begin{tabular}{lccccc}
\hline \multirow{2}{*}{ dyes } & \multicolumn{5}{c}{ Elemental analysis value (\%) } \\
\cline { 2 - 6 } & & $\mathrm{C}$ & $\mathrm{H}$ & $\mathrm{O}$ & $\mathrm{N}$ \\
\hline \multirow{2}{*}{ C.I. Disperse Red 60 } & calculated & 72.50 & 3.93 & 19.33 & 4.23 \\
& observed & 67.91 & 4.04 & 15.82 & 4.36 \\
\hline \multirow{2}{*}{ C.I. Disperse Yellow 3 3} & calculated & 66.91 & 5.58 & 11.90 & 15.56 \\
& observed & 62.86 & 4.34 & 11.55 & 20.05 \\
\hline \multirow{2}{*}{ C.I. Disperse Orange 76 } & calculated & 52.04 & 3.83 & 8.16 & 17.86 \\
& observed & 44.19 & 2.48 & 9.44 & 22.45 \\
\hline
\end{tabular}

\subsection{Dyeing and fastness tests}

Dyeing apparatus used in this experiment was shown in Figure 2. The maximum pressure it can withstand was 400 bar. About $3.5 \mathrm{~g}(6 \mathrm{~cm} \times 15 \mathrm{~cm})$ polypropylene fabric was put into the dye vessel and suitable amount of dye was put in the container before dyeing. The fabric was winded to a circle form. Then the apparatus was sealed and heated to the dyeing temperature we selected while carbon dioxide was pumped simultaneously to the settled pressure. Each of dyeing was maintained for 10 minutes and then released the pressure step by step. At each step, $2.5 \mathrm{MPa}$ of pressure was reduced and temperature still kept at dyeing temperature for 2 minutes until the pressure down to atmosphere. As dyeing process was completed, polypropylene fabric was washed with $2 \mathrm{~g} / \mathrm{l}$ Sunwet $\mathrm{S} 40$ detergent at $60^{\circ} \mathrm{C}$ for 20 minutes, bath ratio $1: 50$ and then rinsed with water. For calculating the dye uptake, we cut $1.5 \mathrm{~g}$ fabric and extracted this colored fabric with $50 \% \mathrm{v} / \mathrm{v}$ pyridine solution and obtained the dye amount by spectrophotometer UV 3000 measurement. Wash and light fastness was tested in accordance with ISO 2 and ISO 105 B05 standard. Instrument of light fastness test was made from James H. Heal company. Fastness grade was decided by ICS Gain Macbeth 20/20 plus spectrophotometer and personal computer.

Figure 2: Diagram of supercritical carbon dioxide dyeing technology

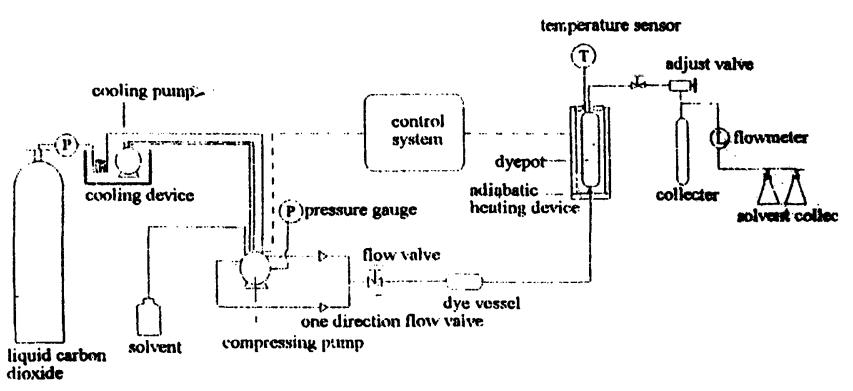

2.3 Analysis and mechanical property test

X-ray diffraction test was carried out by SIEMENS D5000 apparatus to see the micro structure variation of polypropylene fiber. Thermal properties were obtained by using Seiko SSC 5000 DSC and Du Pont 2000 TGA 2050 model. Mechanical property test of warp yarn of fabric was performed by Txtechno H.Stein 050 apparatus and load cell $100 \mathrm{~N}$, preload $0.10 \mathrm{cN} /$ tex , draw ratio $300 \mathrm{~mm} / \mathrm{min}$ and 
gauge length $100 \mathrm{~mm}$.

\section{Results and Discussion}

\subsection{Microscopy analysis}

The observation of fibers cross section from the optical microscopy shown in Figure 3 indicated that dye particles have penetrated thoroughly into fibers. Thus, dyeing polypropylene fabrics with carbon dioxide as a medium was quite feasible. Comparing the dyeing ability of carbon dioxide with that of water in Table 2, dye uptake value of C.I. Disperse Red 60 and C.I. Disperse Orange 76 at $120^{\circ} \mathrm{C}$ by using carbon dioxide as medium were 11.106 and 15.538 $\mu \mathrm{mol} / \mathrm{g}$ respectively, which were 3.78 and 18.9 times higher than in water. Although the dye uptake value from carbon dioxide was not high enough at $100{ }^{\circ} \mathrm{C}$, the dyeing performance was still better than water. At $120^{\circ} \mathrm{C}$, however, the difference of dyeing between carbon dioxide and water was very clear. Because of the low viscosity and hydrophobic nature of carbon dioxide, it can dissolve disperse dye effectively. Dye particles can penetrate into polypropylene fibers much easier in carbon dioxide than in water. Most of all, there was no any auxilliary needed in this supercritical carbon dioxide dyeing process. The cost of waste treatment and energy consumption will be greatly reduced. Hence, it not only can overcome the dyeing difficulty of polypropylene fibers but shows economic as well.

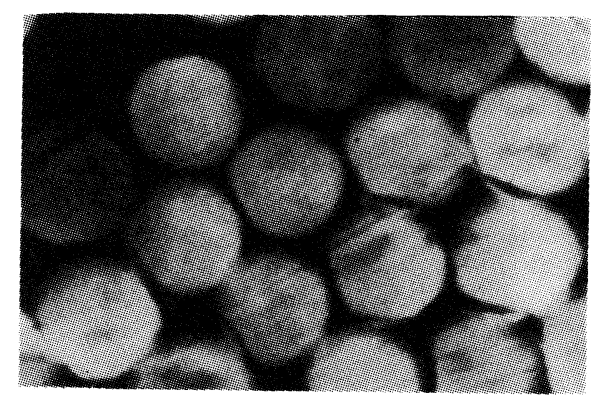

Figure 3: Optical microscopy analysis of fibers cross section

Table 2: Comparison of dye uptake values from carbon dioxide and water dyeing

\begin{tabular}{ccccc}
\hline \multirow{2}{*}{ method } & dyeing & \multicolumn{3}{c}{ Dye uptake $(\mu \mathrm{mol} / \mathrm{g})$} \\
\cline { 3 - 5 } & temperature & Red 60 & Orange 76 & Yellow 3 \\
\hline \multirow{2}{*}{ Dyeing with $\mathrm{CO}_{2}$} & $100^{\circ} \mathrm{C}$ & 3.256 & 6.193 & 0.991 \\
& $120^{\circ} \mathrm{C}$ & 11.106 & 15.538 & 2.028 \\
\multirow{2}{*}{ dyeing with water } & $100^{\circ} \mathrm{C}$ & 1.548 & 0.930 & 0.700 \\
& $120^{\circ} \mathrm{C}$ & 2.932 & 0.822 & 1.007 \\
\hline
\end{tabular}

\subsection{Dyeing and Instruments analysis}

Dye uptake value varied with pressure was shown in Figure 4. Temperature was kept at $120^{\circ} \mathrm{C}$ for 10 minutes with $2 \%$ o.w.f dye amount. From the diagram, we found dye uptake value increased as pressure was raised up to $25 \mathrm{MPa}$, then it decreased significantly at higher pressure $(30 \mathrm{MPa})$. Because the density of carbon dioxide was greatly increasing as it was compressed, the dye can be dissolved more as pressure was increased. When pressure was higher than 25 $\mathrm{MPa}$, however, the density of carbon dioxide changed a little and that the dye migrated back to the carbon dioxide phase easier lead to the decrease in dye uptake. Generally speaking, better leveling result can be got at higher pressures because dye particle can be dissolved more thoroughly but also moved back to fluid phase easier.

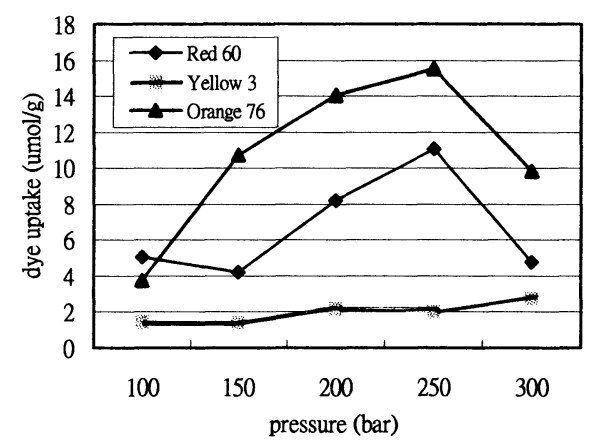

Figure 4: Relations between dye uptake values and pressures

The relation between dye uptake and temperature was shown in Figure 5 in which the dye uptake value increased with the rising of temperature. The reason was that the molecular chain of polypropylene turned to be more mobile at higher temperature and it made the free volume of polypropylene increasing. From the X-ray diffraction curve and pattern shown in Figure 7, four peaks in the diffraction curve became sharper, but arc length of $2 \theta$ of $13^{\circ}$ and $16^{\circ}$ increased as temperature was raised up. Hence our finding was that crystal region has been changed and recrystallization was taken place as polypropylene fibers immersed in carbon dioxide while temperature was set from 100 to $120^{\circ} \mathrm{C}$, but molecular chain orientation was decreasing. Melting heat calculated by DSC analysis was shown in Table 4, phenomena of thermal shrinkage during the dyeing process demonstrated this conception as well. 
Thus, higher dye uptake at higher temperature was mainly due to the decrement of molecular orientation that can lead to the free volume increment. Nevertheless, the results of mechanical property test shown in Table 3 indicated that strength of polypropylene wasn't reduced and shrinkage of yarn was limited (only $5 \%$ ) at $120^{\circ} \mathrm{C}$. TGA analysis in figure 9 also indicated only $1 \%$ of weight was lost while fibers were heated to $200^{\circ} \mathrm{C}$. Hence, the damage of fiber was slight and tolerable when these specimens were dyed at $120^{\circ} \mathrm{C}$. If adequate heat set process had been done onto fiber, the problem of shrinkage and structure change could be minimized. At $130^{\circ} \mathrm{C}$, the crystal region of polypropylene showed clear change and fibers also became harsher. Thus, polypropylene can't be dyed properly at this temperature.

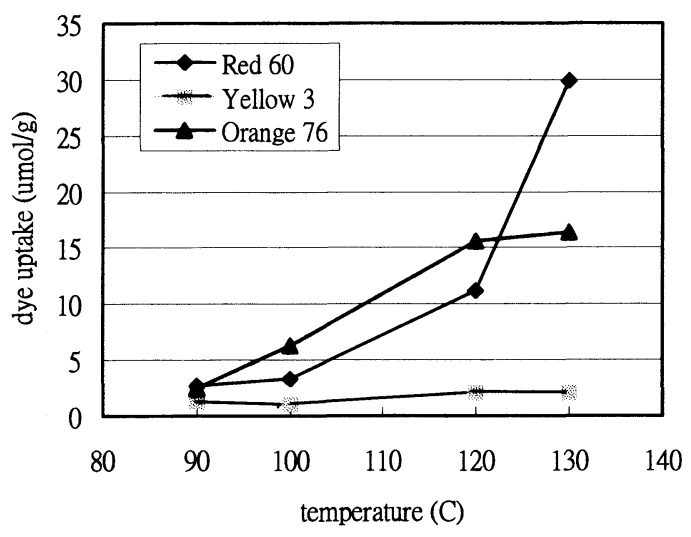

Figure 5: Relations between dye uptake value and temperature for three dyes

The dye uptake value vs. the dye amount was shown in Figure 6, in which dye uptake increased as dye amount was increased, and then reached to a saturated state. About $2 \%$ o.w.f dye amount seemed to be optimum. Comparing the dyeing performance among three dyes, C.I.Disperse Yellow 3 was the worst one for polypropylene. It's low affinity to polypropylene was probably resulted from the existence of amino acetate group in it. C.I.Disperse Red 60 has the best penetration behavior because of its anthraquinone planar structure which has lower hindrance. So that it can penetrate into fibers easier than the other two dyes. In another aspect, it also migrated easier than C.I.Disperse Orange 76 dye, hence the dye uptake was lower than C.I.Disperse Orange 76.

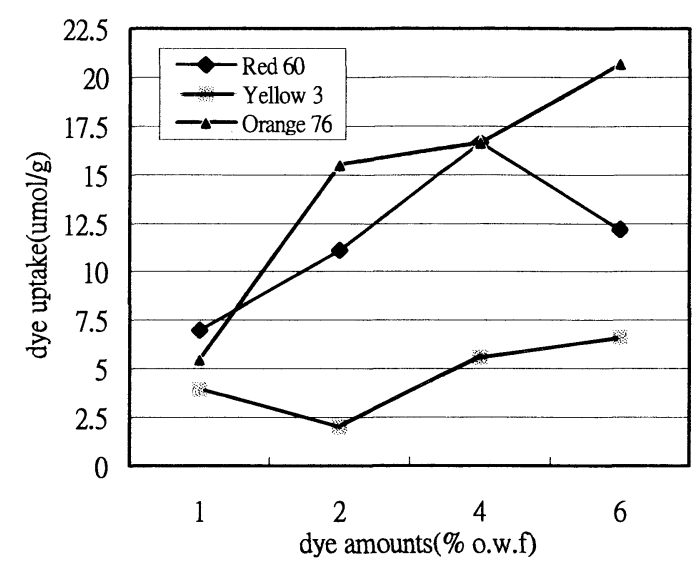

Figure 6: Variation of dye uptake values in accordance with the change of dye amount

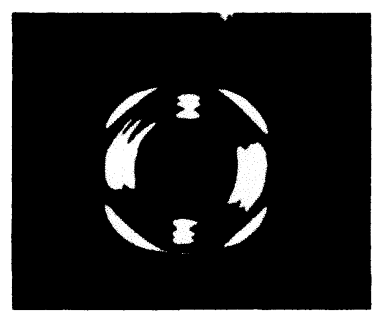

(a)

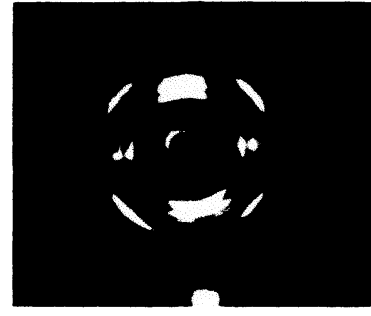

(b)

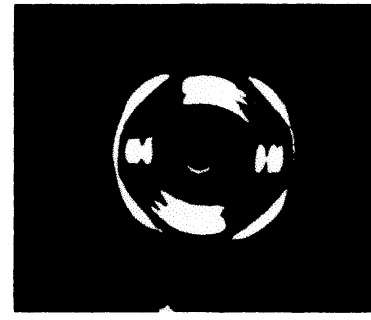

(c)

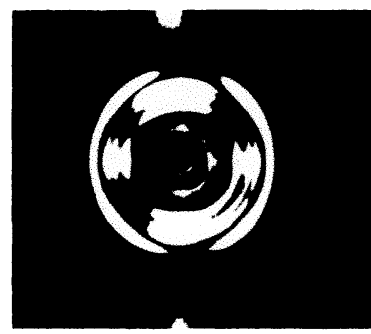

(d)

Figure 7(1): X-ray diffraction pattern of polypropylene fabrics(a: untreated raw fabric, fabric dyed at (b:100 ${ }^{\circ} \mathrm{Cc}: 120$ ${ }^{\circ} \mathrm{C}, \mathrm{d}: 130^{\circ} \mathrm{C}$ ) with 250 bar $\mathrm{CO}_{2}$ ) 

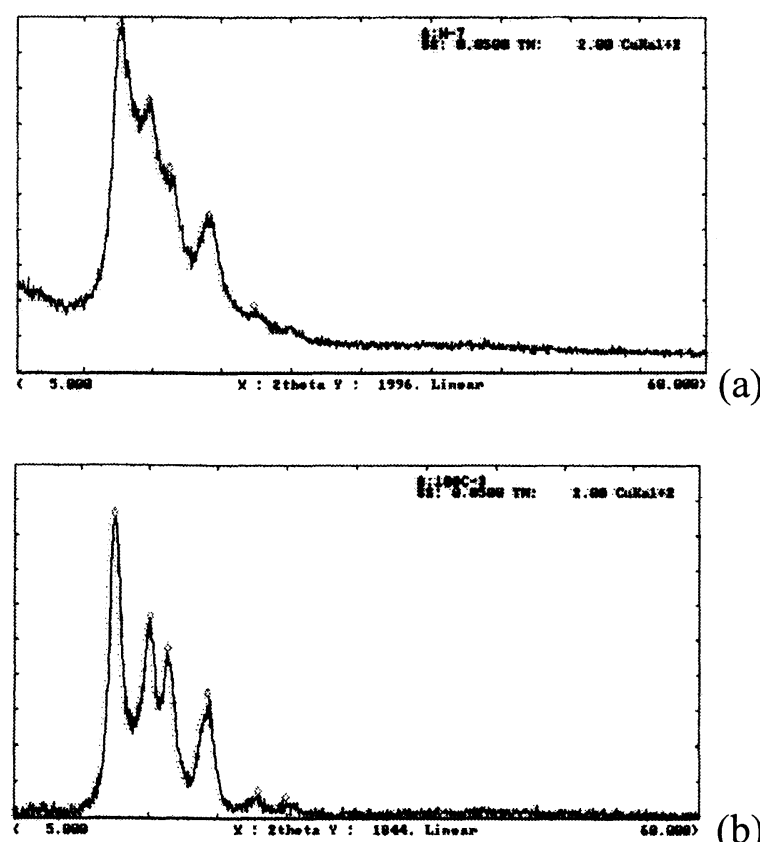

(b)
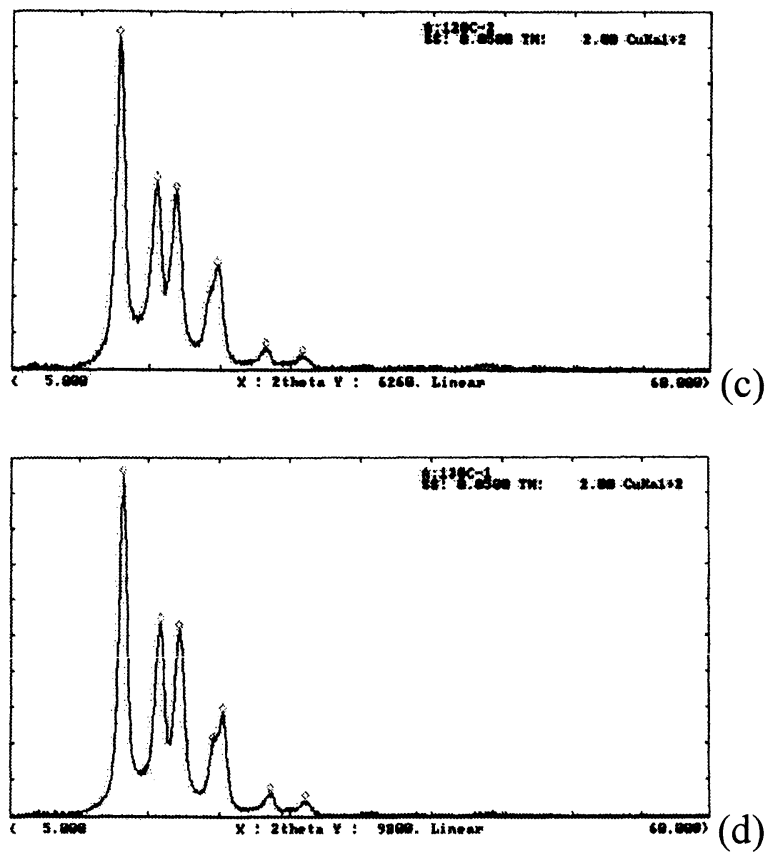

Figure 7(2): X-ray diffraction pattern of polypropylene fabrics(a: untreated raw fabric, fabric dyed at (b:100 ${ }^{\circ} \mathrm{Cc}: 120$ ${ }^{\circ} \mathrm{C}, \mathrm{d}: 130^{\circ} \mathrm{C}$ ) with 250 bar $\mathrm{CO}_{2}$ )

Table 3: Mechanical test results of warp yarn of polypropylene fabric used in this experiment

\begin{tabular}{cccc}
\hline \multirow{2}{*}{ dyeing conditions } & \multicolumn{3}{c}{ mechanical properties } \\
\cline { 2 - 4 } & $\begin{array}{c}\text { Strength } \\
(\mathrm{g} / \mathrm{d})\end{array}$ & $\begin{array}{c}\text { Elongation } \\
(\%)\end{array}$ & $\begin{array}{c}\text { shrinkage } \\
(\%)\end{array}$ \\
\hline $\begin{array}{c}\text { untreated yarn } \\
\text { yarn dyed treated at } 120 \\
{ }^{\circ} \mathrm{C} \text { with } 250 \text { bar } \mathrm{CO}_{2}\end{array}$ & $5.38 \pm 0.14$ & $94.20 \pm 4.48$ & - \\
\hline
\end{tabular}

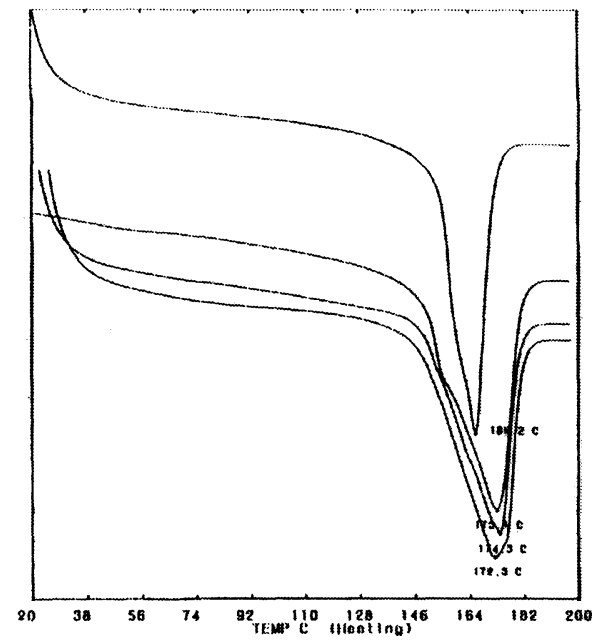

Figure 8: DSC analysis of polypropylene fabrics

(a: untreated raw fabric, fabric dyed at $\left(\mathrm{b}: 100^{\circ} \mathrm{Cc}: 120^{\circ} \mathrm{C}\right.$, d: $130^{\circ} \mathrm{C}$ ) with 250 bar $\mathrm{CO}_{2}$ )

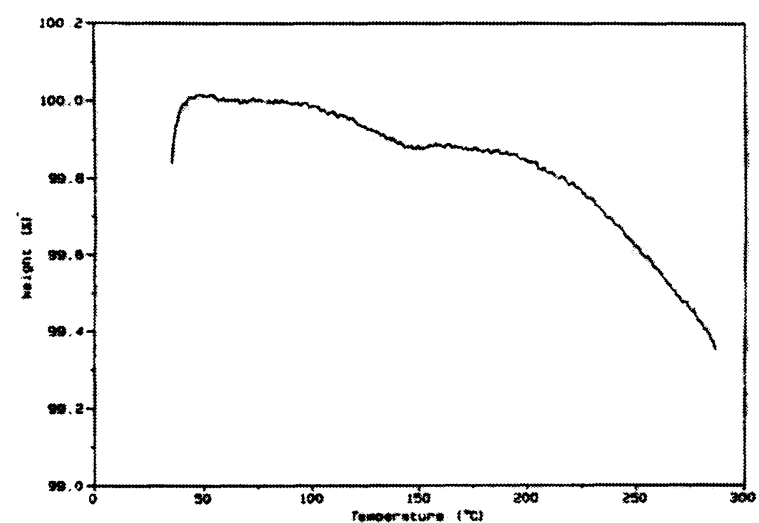

Figure 9: TGA analysis of polypropylene fiber after it was treated at $120^{\circ} \mathrm{C}$ with 250 bar $\mathrm{CO}_{2}$ for 10 minutes

Table 4: Melting heat calculated by DSC analysis

\begin{tabular}{cc}
\hline dyeing conditions & melting heat $(\mathrm{mJ} / \mathrm{mg})$ \\
\hline untreated fiber & 72.5 \\
fiber dyed at $100^{\circ} \mathrm{C}$ with $250 \mathrm{bar} \mathrm{CO}_{2}$ & 74.3 \\
fiber dyed at $120^{\circ} \mathrm{C}$ with $250 \mathrm{bar} \mathrm{CO}_{2}$ & 79.9 \\
fiber dyed at $130^{\circ} \mathrm{C}$ with $250 \mathrm{bar} \mathrm{CO}_{2}$ & 61.5 \\
\hline
\end{tabular}

\subsection{Fastness analysis}

Fastness results showed in Table 5 indicated that all three dyes performed only poor to moderate wash fastness but adequate light fastness. C.I. Disperse Red 60 dye showed better wash fastness but lower light fastness due to its anthraquinone planar structure which gave it better penetrative property and showed more sensitive to light. This is due to the heat effect made the free volume of polypropylene fibers changed, and only physical force 
existed between dye and fibers. Should supercritical carbon dioxide dyeing technology be used for polypropylene, color fixation after treatment must be considered.

Table 4: Wash and light fastness of polypropylene fabrics

\begin{tabular}{ccccccc}
\hline \multirow{2}{*}{ conditions } & \multicolumn{7}{c}{ C.I. Disperse C.I. Disperse C.I. Disperse } \\
& \multicolumn{2}{c}{ Red 60 } & \multicolumn{3}{c}{ Yellow 3 } & \multicolumn{3}{c}{ Orange 76} \\
\cline { 2 - 7 } & wash & light & wash & light & wash & Light \\
\hline $300 \mathrm{bar} \times 120^{\circ} \mathrm{C} \times 2 \% \times 10 \mathrm{~min}$ & 3 & 3 & 1 & 5 & 2 & 5 \\
$250 \mathrm{bar} \times 90^{\circ} \mathrm{C} \times 2 \% \times 10 \mathrm{~min}$ & $3-4$ & $3-4$ & 1 & $3-4$ & 3 & $4-5$ \\
$250 \mathrm{bar} \times 100^{\circ} \mathrm{C} \times 2 \% \times 10 \mathrm{~min}$ & 2 & 5 & 1 & $4-5$ & 3 & 5 \\
$250 \mathrm{bar} \times 120^{\circ} \mathrm{C} \times 2 \% \times 10 \mathrm{~min}$ & $2-3$ & $5-6$ & $1-2$ & 5 & 3 & $5-6$ \\
$250 \mathrm{bar} \times 120^{\circ} \mathrm{C} \times 2 \% \times 1 \mathrm{~min}$ & $3-4$ & 3 & 3 & 6 & $1-2$ & $5-6$ \\
$250 \mathrm{bar} \times 120^{\circ} \mathrm{C} \times 2 \% \times 2 \mathrm{~min}$ & $2-3$ & 6 & 2 & $6-7$ & $1-2$ & $5-6$ \\
$250 \mathrm{bar} \times 120^{\circ} \mathrm{C} \times 2 \% \times 5 \mathrm{~min}$ & $1-2$ & 6 & 3 & $6-7$ & $1-2$ & 6 \\
$250 \mathrm{bar} \times 120^{\circ} \mathrm{C} \times 2 \% \times 30 \mathrm{~min}$ & 2 & $4-5$ & $3-4$ & $6-7$ & 2 & 6 \\
$250 \mathrm{bar} \times 120^{\circ} \mathrm{C} \times 1 \% \times 10 \mathrm{~min}$ & 3 & $4-5$ & $1-2$ & 6 & 2 & 6 \\
$250 \mathrm{bar} \times 120^{\circ} \mathrm{C} \times 4 \% \times 10 \mathrm{~min}$ & $1-2$ & $5-6$ & 1 & 6 & 2 & $5-6$ \\
$250 \mathrm{bar} \times 120^{\circ} \mathrm{C} \times 6 \% \times 10 \mathrm{~min}$ & $2-3$ & $5-6$ & $2-3$ & 6 & 2 & $5-6$ \\
$250 \mathrm{bar} \times 130^{\circ} \mathrm{C} \times 2 \% \times 10 \mathrm{~min}$ & $2-3$ & 6 & 1 & $3-4$ & 3 & $6-7$ \\
$200 \mathrm{bar} \times 120^{\circ} \mathrm{C} \times 2 \% \times 10 \mathrm{~min}$ & $3-4$ & $4-5$ & 1 & $5-6$ & 3 & 5 \\
$150 \mathrm{bar} \times 120^{\circ} \mathrm{C} \times 2 \% \times 10 \mathrm{~min}$ & $3-4$ & $3-4$ & 1 & 5 & 2 & 5 \\
$100 \mathrm{bar} \times 120^{\circ} \mathrm{C} \times 2 \% \times 10 \mathrm{~min}$ & 2 & 3 & 1 & 5 & $2-3$ & $5-6$ \\
Water dyeing $\times 120^{\circ} \mathrm{C} \times 45 \mathrm{~min}$ & $3-4$ & $3-4$ & $1-2$ & $3-4$ & 2 & 3 \\
Water dyeing $\times 100^{\circ} \mathrm{C} \times 45 \mathrm{~min}$ & $2-3$ & $2-3$ & 1 & $3-4$ & $2-3$ & 3 \\
\hline
\end{tabular}

\section{Conclusion}

Dyeing of polypropylene fibers with disperse dye by supercritical carbon dyeing technology was quite feasible because of the excellent permeability of carbon dioxide into polypropylene and its good compatibility with disperse dye. These characters made dye particles penetrate into fiber easier than the usage of water as medium. X-ray diffraction and DSC thermal analysis results demonstrated that recrystallization was produced as polypropylene fibers were dyed in carbon dioxide at $120^{\circ} \mathrm{C}$. Orientation decrement of polymer chain was the main factor which can influent the dyeing results. Free volume increment from X-ray and DSC analysis proved that disperse dye could dye polypropy -lene. Increasing pressure could dissolve dye well and higher temperature (near $120^{\circ} \mathrm{C}$ ) made polypropylene be dyed more easier due to the increment of molecular chains free volume. From our study, the optimal dyeing conditions were suggested that polypropylene was dyed with $2 \%$ o.w.f dye for 10 minutes as pressure near $250 \mathrm{bar}$ and temperature up to $120^{\circ} \mathrm{C}$.

The result of TGA analysis and tensile test indicated damage of polypropylene fiber was limited when temperature raised up to $120^{\circ} \mathrm{C}$. Wash fastness could be the main problem on this process. If suitable fixation after treatment had been adopted, this problem should have been limited. Consider about these conceptions described above, dyeing polypropylene fabric with carbon dioxide need further study to improve the wash fastness problems. And then, the diffusion behavior will be able to be understood. Thus the feasibility of dyeing polypropylene should be solved economically without any risks in fiber damage.

\section{Acknowledgement}

The author acknowledges the support by the directed research and development funds and instrument analysis from National Science Council in their NSC-89-2216-E -035-010 plan.

\section{Reference}

1.P.Galli, S.Danesi and T.Simonazzi, Poly.Eng.and Sci., Mid-June, 24, p544-554 (1984)

2.AATCC, metropoliton section,"The Dyeing of Polypropylene for Textiles" Amer.Dyest.Rep. 54, p107-114 (1965) 3.C.D.Shah and D.K.Jain, Text.Res.J.,.53, p274-281 (1983) 4.C.D.Shah and D.K.Jain, Text.Res.J.,.54, p742-748 (1984) 5.J.Akrman and M.Kaplanova, JSDC, 111, p159-163 (1995) 6.J.Akrman and J.Prikryl, J.Appl.Poly.Sci., 62, p235-245 (1996)

7.J. Akrman and J. Prikryl, J.Appl.Poly.Sci., 66, p543-550 (1997)

8.C.Pugh and Y.L.Hsieh, J.Appl.Poly.Sci., 29, p3641-3649 (1984)

9.A.K.Mukherjee and B.D.Gupta, J.Appli.Poly.Sci., 30, p 4455-4466 (1985)

10.A.K.Mukherjee and B.D.Gupta, JSDC, 104, p130-133 (1988)

11.S.R.Shukla and A.R.Athalye, J. Appli .Poly. Sci., .51, p1567-1574 (1994)

12.I.K.Mehta, B.N.Misra and G.S.Chauhan, J. Appli. Poly. Sci., 54, p1171-1178 (1994)

13.S.II.Hong, S.T.Kim and T.S.Lee, JSDC, 110, p19-23, (1994)

14.A.Seves, T.De Marco and A.Siciliano, Dyes and Pigment, 28, p19-29 (1995) 
15.Jiri Akrman, Josef Prikryl and Ladislav Burgert JSDC, 114, p209-215 (1998)

16.W.Saus, D.Knittel and E.Schollmeyer, Text.Res.J., 63, p135-142 (1993)

17.B.Gebert, W.Saus, D.Knittel, H.J. Buschmann and E.Schollmeyer, Text.Res.J., 64, p371-374 (1994)

18.Wolfgang Saus, Jasper GmbH, May, p145-150 (1995)

19.A.S.Ozcan, A.A.Clifford, K.D.Bartle, P.J.Broadbent and D.M.Lewis, JSDC,114, p169-173 (1998)

20.Y.T.Shieh, J.H.Su, G.Manivannan, P.H.C.Lee, S.P.Sawan and W.D.Spall J.Appl.Poly.Sci., 59, p695-705 (1996) 